\title{
EFEITO DE DIFERENTES PORTA-ENXERTOS SOBRE O DESENVOLVIMENTO E PRODUÇÃO DE FIGO VERDE, PELA VARIEDADE ROXO DE VALINHOS
}

\author{
Bruna Guerreiro Casaroti ${ }^{1}$, Gustavo Alves Pereira ${ }^{2}$, Luiz de Souza Corrêa ${ }^{3}$
}

\footnotetext{
${ }^{1}$ Engenheira Agrônoma - Monsanto, São Paulo (SP).

${ }^{2}$ Docente do Departamento de Ciências Vegetais-Universidade Federal do Semi-Árido, Mossoró (RN).

${ }^{3}$ Docente do Departamento de Fitotecnia, Tecnologia de Alimentos e Sócio Economia - Faculdade de Engenharia / UNESP Campus de Ilha Solteira (SP).
}

RESUMO: A figueira (Ficus carica), uma planta da família Moraceae, é umas das frutíferas mais antigas do mundo. Seu principal método de propagação é a estaquia, sendo que essa apresenta algumas falhas. O objetivo do presente trabalho foi avaliar o efeito de diferentes porta-enxertos sobre o desenvolvimento bem como produção da figueira variedade Roxo de Valinhos. O trabalho foi realizado na Fazenda de Ensino e Pesquisa da Faculdade de Engenharia - UNESP, campus Ilha Solteira, localizada no município de Selvíria, MS, no período de 03 de abril de 2009 a 27 de março de 2010. Foram avaliados 10 diferentes porta-enxertos (Calimyrna, Genovesco, Roxo de Valinhos, Celeste, Bonato, White Genova, Pingo de Mel IAC, Pingo de Mel, Caprifigo e Troyano). Avaliou-se o número de frutos colhidos por planta e época de colheita, comprimento médio e massa seca dos ramos ao final da colheita. O porta-enxerto que apresentou os melhores resultados para os parâmetros analisados foi o Bonato.

Palavras-chave: Ficus carica L. Enxertia. Roxo de Valinhos.

\section{EFFECT OF DIFFERENT ROOTSTOCKS ON THE DEVELOPMENT AND PRODUCTION OF FIGO GREEN, PURPLE BY VARIETY OF VALINHOS}

\begin{abstract}
The fig (Ficus carica), a plant family Moraceae, is one of the world's oldest fruit. His principal method of propagation is by cutting, and this has some flaws. The aim of this study was to evaluate the effect of different rootstocks on the development and production of the fig variety Purple Valinhos. The study was conducted at the Teaching and Research Farm, Faculty of Engineering - UNESP, Single Island, located in Selvíria, MS, from 3 April 2009 to 27 March 2010. We evaluated 10 different rootstocks (Calimyrna, Genovesco, Purple Valinhos, Celeste, Bonato, White Genoa, Pingo de Mel IAC, Pingo de Mel, caprifig and Troyano). We evaluated the number of fruits per plant and harvest time, length and dry mass of branches at the final harvest. The rootstock that showed the best results for the parameters analyzed was Bonato.
\end{abstract}

Key words: Ficus carica L. Grafting. Purple Valinhos.

Cultura Agronômica, Ilha Solteira, v.24, n.2, p.225-233, 2015 


\section{INTRODUÇÃO}

A figueira (Ficus carica L.) é uma das mais antigas frutíferas cultivadas no mundo e originária do Oriente Médio. Apresenta excelente adaptação as diferentes climas, sendo assim cultivada tanto em regiões subtropicais quentes, como em regiões de clima temperado.

Foi introduzida no Brasil pela expedição colonizadora no ano de 1532 (ABRAHÃO et al., 1990). Já o seu cultivo comercial, data do início do século passado, mais precisamente, a partir de 1910, na cidade paulista de Valinhos (CORRÊA; BOLIANI, 1999)

O Brasil, com o figo do tipo Comum Roxo de Valinhos, e a Turquia, com o figo polinizado do tipo Smirna, destacam-se na produção de figos para abastecimento do mercado internacional, pois os demais países produtores (cerca de quarenta, localizados principalmente, na Bacia Arábica do Mar Mediterrâneo) destinam seus frutos ao abastecimento interno.

Segundo o IEA (2008), o figo está entre as vinte principais frutas exportadas pelo Brasil e vem mantendo a terceira posição no ranking de volume comercializado. Porém apresenta grandes possibilidades de aumento de comercialização devido as pesquisas demonstrarem que a cultura não necessita de frio para completar o repouso e iniciar sua fase reprodutiva, o que amplia a possibilidade de seu plantio para regiões mais quentes do que as tradicionais, uma vez que o mercado de consumo interno e, principalmente, externo existe e é bastante promissor.

Dentre os problemas que afetam a cultura da figueira, no campo, podemos destacar três: a seca da figueira, doença causada pelo fungo Ceratocystis fimbriata; A ferrugem, outra doença fungica, esta causada por Cerotelium fici, e que é um fator limitante na produção comercial da cultura; e os nematóides, que como vivem no solo, possuem como principal meio de disseminação o transporte de mudas infectadas.

Por esses motivos é de fundamental importância avaliar métodos de propagação da cultura da figueira. Segundo Souza (2008) a enxertia que é uma das formas de propagação das frutíferas, e em relação à cultura da figueira, poderá vir a ser uma forma de aumentar a produção, levando-se em consideração os danos causados por nematóides e a existência de variedades e espécies tidas como resistentes ou tolerantes a essa praga.

Diante desta situação, o presente trabalho teve como objetivo avaliar o efeito de diferentes porta-enxertos, sobre o desenvolvimento da figueira variedade Roxo de Valinhos, para produção de figos verdes.

\section{MATERIAL E MÉTODOS}

O experimento foi conduzido na fazenda experimental da Faculdade de Engenharia de Ilha Solteira - UNESP, Selvíria, MS, cujas coordenadas geográficas são $51^{\circ} 22^{\prime} \mathrm{W}$ e $20^{\circ} 22^{\prime} \mathrm{S}$, com $335 \mathrm{~m}$ de altitude, apresentando média anual de $24,5^{\circ} \mathrm{C}, 1.370 \mathrm{~mm}$ e $64,8 \%$, respectivamente, para temperatura, precipitação e umidade relativa. O solo do local foi Cultura Agronômica, Ilha Solteira, v.24, n.2, p.225-233, 2015 
classificado como Latossolo Vermelho distrófico (LVd), fase cerrado tropical subcaducifólio (EMBRAPA, 2006). Cada repetição do experimento era composta por 10 variedades de porta enxerto, sendo todos eles enxertados com a copa da variedade Roxo de Valinhos. As plantas ao final das avaliações tinham 10 ramos, ainda produzindo frutos. Os tratos culturais e as avaliações do experimento começaram no dia 03 de abril de 2009 e terminaram no dia 27 de março de 2010. O experimento consistiu em 10 variedades de porta-enxertos, tendo como copa ou enxerto a variedade Roxo de Valinhos.

Os porta-enxertos utilizados foram:

- Porta-enxerto variedade Calimyrna: foi cultivada na Turquia por vários séculos. Foi introduzida na Califórnia, em vários momentos, sendo que o plantio comercial ocorreu pela primeira vez em 1886. Planta vigorosa, com hábito de crescimento vertical e folhas de tamanho médio a grande. Os frutos são grandes com peso médio de 70 gramas, com pescoço grosso, curto e achatado, apresenta sabor agradável, excelente qualidade para consumo in natura e seco (CONDIT, 1955);

- Porta-enxerto variedade Genovesco: é relatada como variedade comum no norte da Itália, sendo posteriormente introduzida nos Estados Unidos. Planta de crescimento lento, com muitos galhos pequenos, finos e brotos terminal verde. Frutos de formato oblíquopiriforme, peso médio de 28 gramas, apresenta sabor doce, mas é seco na textura (má qualidade). Uma porcentagem considerável da safra cai quando os frutos são pequenos (CONDIT, 1955).

- Porta-enxerto variedade Roxo de Valinhos: O Roxo de Valinhos é uma variedade do tipo comum, de grande valor econômico, caracterizando-se por rusticidade, vigor e produtividade. É a variedade que melhor tem se adaptado ao sistema de poda drástica usada nas principais regiões produtoras, mantendo, por isso um porte arbustivo e a frutificação somente em ramos do ano. Os frutos apresentam coloração roxo-violácea escura, alcançando cerca de 7,0 cm de comprimento e 60 a 90 gramas de peso. São de formato oblongo-piriformes, de pescoço curto e grosso. A película é espessa tenra, com pontuações visíveis, mudando de tonalidade à medida que a maturação avança. A polpa mostra a coloração róseo-avermelhada característica, com cavidade central, é sucosa, macia e de sabor agridoce agradável (PEREIRA, 1981).

- Porta-enxerto variedade Celeste: foi introduzida no sul dos Estados Unidos entre 1860 e 1870. Em virtude do pequeno tamanho do fruto não foi cultivada comercialmente. Planta de vigor moderado, caule fino, frutos com peso médio de 30 gramas, de formato piriforme com o pescoço afinando gradualmente a partir do corpo do caule (CONDIT, 1955).

- Porta-enxerto variedade Bonato: variedade do grupo Korfu é vigorosa e produtiva produzindo figos grandes, globoso-piriformes, de colocração roxa, polpa rosado-clara, de bom paladar e maturação em meados de fevereiro (MAIORANO et al., 1997).

- Porta-enxerto variedade White Genova: Em 1853, a variedade White Genova foi introduzida na estação experimental de Califórnia. Plantas de vigor moderado com galhos espalhados e folhas grandes. Apresenta frutos grandes com peso médio de 80 gramas com 
formato oblíquo-piriforme, pescoço curto ou às vezes curvado, pedúnculo curto, polpa de textura gelatinosa, sabor suave, baixa qualidade e suscetível a deterioração (CONDIT, 1955).

- Porta-enxerto variedade Pingo de Mel IAC: Essa variedade é também conhecida como Dottado, Kadota, White Pacific. É uma variedade bastante vigorosa e produtiva, adaptandose bem ao sistema de poda drástica. Os figos são de tamanho médio, fechado, de cor amarela-esverdeada (limão) e apresenta polpa cor âmbar, sem cavidade, paladar e bastante doce (MAIORANO et al., 1997).

- Porta-enxerto variedade Pingo de Mel: A variedade Pingo de Mel, também conhecida como Dottado, embora tenha sido cultivada em algumas regiões, praticamente não apresenta importância econômica no Brasil. É uma variedade bastante produtiva e vigorosa, os frutos são de tamanho médio, piriformes, com pedúnculo médio, ostíolo de tamanho médio e fechado. É utilizada basicamente, para o consumo "in natura", porém apresenta potencial para áreas destinadas à industrialização. E assim como a variedade Roxo de Valinhos, adapta-se bem ao sistema de poda drástica (MAIORANO et al. 1997).

- Porta-enxerto variedade Caprifigo: Abrange as figueiras selvagens, cujos sicônios normalmente não são comestíveis. Apresentam flores femininas de estilo curto e flores masculinas, encontram-se distribuídas na região próxima ao ostíolo. As flores femininas são adaptadas à ovoposição das vespinhas da espécie Blastophaga psenes L., as quais são agentes naturais de polinização em $F$. carica (CONDIT, 1955).

- Porta enxerto variedade Troyano: Troyano consiste em uma variedade extensivamente cultivada sendo muito apreciada para a produção de frutos ao final do verão e início do outono. Foi introduzida em 1878 na Califórnia. Planta vigorosa que apresenta frutos pequenos com peso médio de 35 gramas. Devido ao tamanho dos frutos não é indicada para compotas (CONDIT, 1955).

Os tratamentos utilizados foram os seguintes:

1- Porta-enxerto variedade Calimyrna/enxerto variedade Roxo de Valinhos;

2- Porta-enxerto variedade Genovesco/enxerto variedade Roxo de Valinhos;

3- Porta-enxerto variedade Roxo de Valinhos/enxerto variedade Roxo de Valinhos;

4- Porta-enxerto variedade Celeste/enxerto variedade Roxo de Valinhos;

5- Porta-enxerto variedade Bonato/enxerto variedade Roxo de Valinhos;

6- Porta-enxerto variedade White Genova/enxerto variedade Roxo de Valinhos;

7- Porta-enxerto variedade Pingo de Mel IAC/enxerto variedade Roxo de Valinhos;

8- Porta-enxerto variedade Pingo de Mel/enxerto variedade Roxo de Valinhos;

9- Porta-enxerto variedade Caprifigo/enxerto variedade Roxo de Valinhos;

10- Porta enxerto variedade Troyano/enxerto variedade Roxo de Valinhos;

O delineamento experimental utilizado foi o de blocos inteiramente casualizados, contendo 10 tratamentos, com 3 repetições e 1 planta por parcela, no espaçamento $2,5 \mathrm{x}$ 
1,5m. A poda de produção foi realizada no dia 03 de abril de 2009, sendo podados 6 ramos. No dia 05 de maio do mesmo ano fez-se a primeira desbrota onde foram selecionados dois brotos por ramo podado, eliminando-se os demais. No dia 20 de agosto foi realizada outra desbrota, eliminando brotos que apareceram sobre o ramo em produção. No dia 17 de novembro de 2009 foi feito um desponte, com objetivo de duplicar o número de ramos produtivos. Após o desponte, no dia 02 de dezembro de 2009, foi retirado o excesso de brotos novos, ficando cerca de 10 brotos por planta, sendo estes os mais vigorosos. $\mathrm{O}$ presente experimento teve como variáveis analisadas o número de frutos produzidos por planta, o comprimento dos ramos em sua fase final e a massa seca por ramo. Foram realizadas 6 colheitas, efetuadas nos meses de agosto, setembro, outubro e dezembro de 2009, bem como janeiro e fevereiro de 2010, nas quais foram realizadas a contagem dos frutos e obtido o número de frutos por planta. Os ramos foram medidos no dia 04 de março de 2010, sendo utilizado 5 ramos de cada planta, escolhidos ao acaso. Para obtenção da massa seca dos ramos, realizou-se uma coleta no dia 26 de março, sendo utilizado um ramo de tamanho médio de cada planta, dos quais foram retiradas todas as brotações e folhas. Em seguida, os ramos foram colocados em estufa de circulação forçada de ar, mantida a $65^{\circ} \mathrm{C}$ até peso constante, momento em que se obteve a massa seca por ramo.

\section{RESULTADOS E DISCUSSÃO}

Na tabela 1 é apresentado o número médio de figos verdes produzidos pela variedade Roxo de Valinhos, cultivada sobre vários porta-enxertos, na região de Ilha Solteira, SP.

Tabela 1. Número de frutos verdes colhidos por planta de figueiras, variedade Roxo de Valinhos, sobre vários porta-enxertos, no ano agrícola 2009/2010. Ilha Solteira, SP.

\begin{tabular}{lcccc}
\hline \multicolumn{1}{c}{ Porta-Enxertos } & \multicolumn{5}{c}{$\mathbf{n}^{\mathbf{0}}$ frutos /repetição } \\
\hline T1 - Calimyrna & $\mathbf{R 1}$ & $\mathbf{R 2}$ & $\mathbf{R 3}$ & Média \\
\cline { 2 - 5 } T2 - Genoveso & 111 & 80 & 114 & $101,67 \mathrm{bc}$ \\
T3 - Roxo de Valinhos & 134 & 85 & 76 & $98,33 \mathrm{bc}$ \\
T4 - Celeste & 130 & 79 & 118 & $110,00 \mathrm{bc}$ \\
T5 - Bonato & 120 & 17 & 17 & $52,33 \mathrm{~d}$ \\
T6 - White Genova & 181 & 192 & 170 & $191,67 \mathrm{a}$ \\
T7 - Pingo de Mel IAC & 150 & 57 & 103 & $105,00 \mathrm{bc}$ \\
T8 - Pingo de Mel & 112 & 64 & 84 & $87,33 \mathrm{~cd}$ \\
T9 - Caprifigo & 70 & 74 & 85 & $76,33 \mathrm{~cd}$ \\
T10 - Troyano & 98 & 63 & 95 & $86,00 \mathrm{~cd}$ \\
\hline CV \% = 22,69 & 164 & 125 & 114 & $136,67 \mathrm{~b}$ \\
\hline
\end{tabular}

Médias seguidas por letras iguais na coluna, não diferem entre si pelo Teste de Duncan ao nível de 5\%

Pelos dados e análise efetuada, constata-se que houve diferença estatística significativa entre os tratamentos. Os resultados mostram que a maior produção foi obtida quando foi utilizado o porta-enxerto da variedade Bonato (191,67 frutos/planta). Em seguida aparecem os porta-enxertos das variedades Troyano, Roxo de Valinhos, White Genova

Cultura Agronômica, Ilha Solteira, v.24, n.2, p.225-233, 2015 
Calimyrna e Genoveso, que não diferiram estatisticamente entre si, mas diferiram do Bonato.

As produções obtidas por Vieira et al. (2008) em Macaé, RJ, para diferentes épocas de poda para produção de figo verde foram: em julho 73 frutos/planta e em março 139 frutos/planta. As podas de maio, setembro e novembro deram produções inferiores à obtida no mês de julho.

Tal fato evidencia que as variedades de porta-enxertos Bonato, Troyano, Roxo de Valinhos, White Genova, Calimyrna e Genoveso, apresentaram boa produção de frutos por planta. Evidencia também que houve uma excelente afinidade com a variedade copa (Roxo de Valinhos), o que está de acordo com os postulados sobre enxertia (SIMÃO, 1998), deixando claro, que a enxertia em figueiras é um processo viável e que dá origem a combinações com excelentes produtividades.

Segundo Santos (1997) a poda no período entre abril e maio prolonga muito o período vegetativo das plantas, retardando, desse modo, o início da primeira colheita. Porém, no experimento realizado, observou-se uma maior quantidade de frutos, para algumas variedades de porta enxertos, no mês de setembro, período ainda de entressafra. No entanto, o período em que houve uma média maior do número de frutos colhidos para todas as variedades avaliadas, foi o período de safra, que corresponde aos meses de dezembro, janeiro e fevereiro, como pode ser observado na figura 1.

Com base nos dados contidos no anexo 2, pode-se concluir que o clima não foi um fator que afetou o número de frutos colhidos, pois nas épocas que houve o maior número de frutos (os meses de setembro, dezembro, janeiro e fevereiro) a temperatura era semelhante a dos outros períodos de colheita.

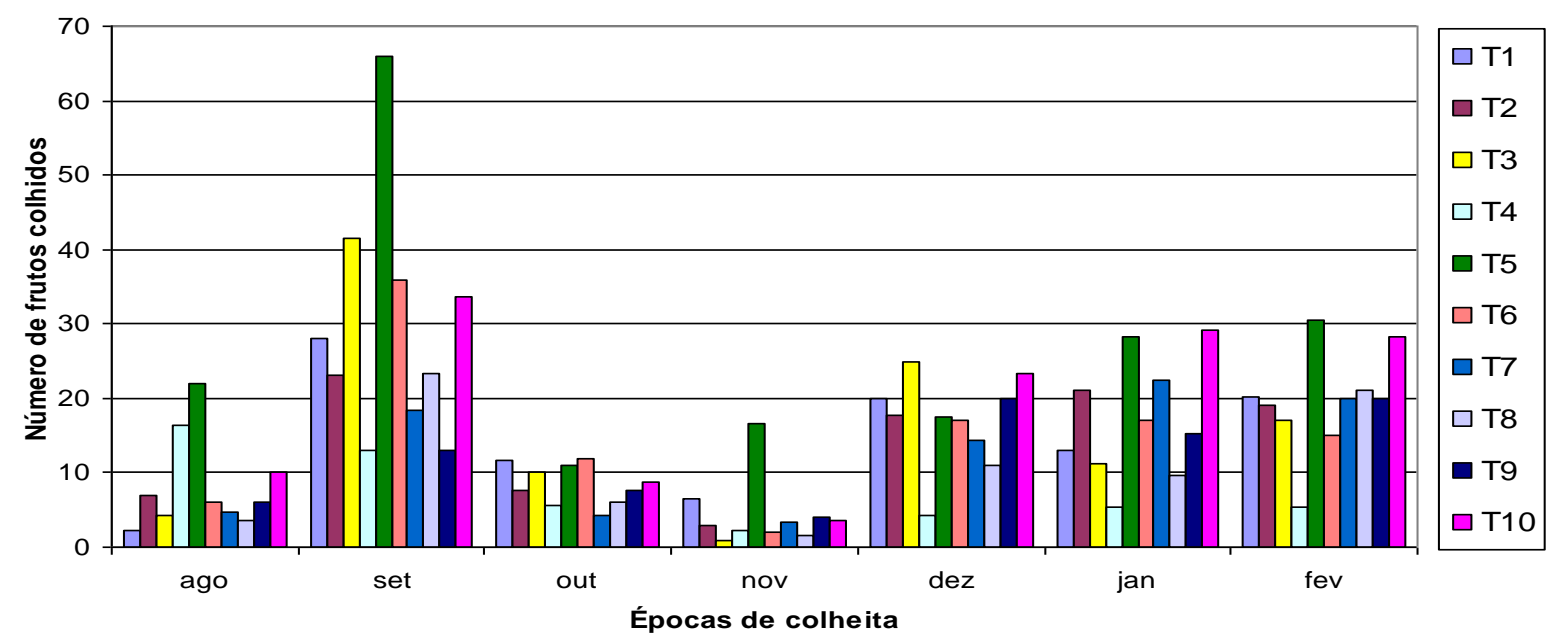

Legenda: séries: 1) T1- Calimyrna, 2) T2- Genoveso, 3) T3- Roxo de Valinhos, 4) T4- Celeste, 5) T5- Bonato, 6) T6- White Genova, 7) T7- Pingo de Mel IAC, 8) T8- Pingo de Mel, 9) T9-Caprifigo e 10) T10- Troyano

Figura 1. Efeitos dos porta-enxertos sobre o número de figos verdes colhidos em cada tratamento, nas diferentes épocas.

Na tabela 2 encontra-se o resultado da avaliação feita no dia 04 de março de 2010, com o comprimento médio dos ramos. Verifica-se que houve diferença estatística entre os

Cultura Agronômica, Ilha Solteira, v.24, n.2, p.225-233, 2015 
tratamentos, porém apenas o porta-enxerto da variedade Celeste diferiu dos demais. A variedade Celeste é a única que é tida como resistente aos nematóides, no entanto, apresentou o menor crescimento.

Tabela 2. Comprimento médio dos ramos ao final da colheita por planta de figueira cultivar Roxo de Valinhos sobre vários porta-enxertos, no ano agrícola 2009/2010. Ilha Solteira, SP.

\begin{tabular}{lcccc}
\hline \multicolumn{1}{c}{ Porta-Enxertos } & \multicolumn{5}{c}{ Compr.ramo (cm) / repetição } \\
\hline & R1 & R2 & R3 & Média \\
\cline { 2 - 5 } T1 - Calimyrna & 138 & 110 & 129 & $125,67 \mathrm{a}$ \\
T2 - Genoveso & 151 & 108 & 113 & $124,00 \mathrm{a}$ \\
T3 - Roxo de Valinhos & 122 & 119 & 138 & $126,33 \mathrm{a}$ \\
T4 - Celeste & 90 & 51 & 158 & $66,67 \mathrm{~b}$ \\
T5 - Bonato & 140 & 152 & 127 & $139,67 \mathrm{a}$ \\
T6 - White Genova & 139 & 131 & 135 & $135,00 \mathrm{a}$ \\
T7 - Pingo de Mel IAC & 128 & 127 & 112 & $122,33 \mathrm{a}$ \\
T8 - Pingo de Mel & 149 & 132 & 114 & $131,67 \mathrm{a}$ \\
T9 - Caprifigo & 144 & 152 & 092 & $129,33 \mathrm{a}$ \\
T10 - Troyano & 128 & 117 & 112 & $119,00 \mathrm{a}$ \\
\hline CV \% = 12,10 & \multicolumn{5}{c}{} \\
\hline Médias seguidas por letras iguais na coluna, não diferem entre si pelo Teste de Duncan ao nível de 5\%.
\end{tabular}

O que pode ser sugerido quanto a variedade Celeste, já que mesmo ela não apresentando bons resultados quanto ao comprimento dos ramos ela é de grande importância dada a sua resistência aos nematóides, é reduzir o espaçamento utilizado nesse experimento $(2,5 \mathrm{~m} \times 1,5 \mathrm{~m})$ pela metade $(1,25 \mathrm{~m} \times 0,75 \mathrm{~m})$.

Em trabalho realizado por Gonçalves et al. (2006), na região norte mineira, as épocas de poda e o sistema de condução da figueira, afetaram isoladamente o crescimento total dos ramos nos ciclos agrícolas avaliados (2000/2001 e 2001/2002). No ciclo de poda 2000/2001, plantas podadas em março e junho apresentaram maior crescimento total dos ramos em relação a setembro e dezembro. Em relação às plantas podadas no ciclo 2001/2002, as podadas em junho apresentaram maior crescimento total de ramos em comparação à poda de dezembro, não diferindo em relação a setembro e março.

Na tabela 3, encontra-se a massa seca dos ramos, que também mostrou diferença estatística significativa entre os tratamentos. Destaca-se nessa avaliação o bom desempenho dos porta enxertos das variedades Calimyrna (83,33g/ramo), Genoveso (71,67g/ramo), Bonato (85,67g/ramo), White Genova (76.67g/ramo), Pingo de Mel (73,33g/ramo) Caprifigo (63,33g/ramo) e Troyano (80,00g/ramo), as quais não diferiram das variedades Roxo de Valinhos e Pingo de Mel IAC, mas diferiram da variedade Celeste. Observa-se que, mesmo não tendo uma diferença estatística significativa, a variedade de porta-enxerto Bonato teve um desempenho de 22,34g a mais, do que a cultivar Caprifigo.

Cultura Agronômica, Ilha Solteira, v.24, n.2, p.225-233, 2015 
Tabela 3. Massa seca média ( $g$ ) dos ramos ao final da colheita por planta de figueira cultivar Roxo de Valinhos sobre vários porta-enxertos, no ano agrícola 2009/2010. Ilha Solteira, SP.

\begin{tabular}{lcccc}
\hline \multicolumn{1}{c}{ Porta-Enxertos } & \multicolumn{4}{c}{ g/ramo/repetição } \\
\hline T1 - Calimyrna & R1 & R2 & R3 & Média \\
\cline { 2 - 5 } T2 - Genoveso & 105 & 90 & 85 & $83,33 \mathrm{a}$ \\
T3 - Roxo de Valinhos & 90 & 75 & 80 & $71,67 \mathrm{a}$ \\
T4 - Celeste & 65 & 45 & 85 & $55,00 \mathrm{ab}$ \\
T5 - Bonato & 65 & 25 & 10 & $26,67 \mathrm{~b}$ \\
T6 - White Genova & 98 & 120 & 75 & $85,67 \mathrm{a}$ \\
T7 - Pingo de Mel IAC & 110 & 65 & 88 & $76,67 \mathrm{a}$ \\
T8 - Pingo de Mel & 50 & 80 & 70 & $56,67 \mathrm{ab}$ \\
T9 - Caprifigo & 70 & 80 & 100 & $73,33 \mathrm{a}$ \\
T10 - Troyano & 70 & 80 & 70 & $63,33 \mathrm{a}$ \\
\hline CV \% = 26,30 & 75 & 95 & 10 & $80,00 \mathrm{a}$ \\
\hline
\end{tabular}

Médias seguidas por letras iguais na coluna, não diferem entre si pelo Teste de Duncan ao nível de 5\%.

\section{CONCLUSÕES}

- Com relação à produção de frutos, os melhores porta-enxertos foram das variedades Bonato seguido de Troyano, Roxo de Valinhos, White Genova, Calimyrna e Genoveso;

- Os maiores acúmulos de massa seca nos ramos, foram obtidos com os porta-enxertos das variedades Bonato, Calymirna, Troyano, White Genova, Pingo de Mel, Genoveso e Caprifigo;

- O porta-enxerto variedade Celeste apresentou o menor desenvolvimento e produção de frutos;

- Em todos os porta-enxertos utilizados contatou-se dois picos de alta produção de frutos um em setembro e outro nos meses de dezembro, janeiro e fevereiro.

\section{REFERÊNCIAS BIBLIOGRÁFICAS}

ABRAHÃO, E.; CHALFUN, N.; REGINA, M.; ALVARENGA, A. Influência de diferentes tipos de poda no desenvolvimento e produção da figueira (Fícus carica L.) Roxo de Valinhos. Revista Brasileira de Fruticultura, Cruz das Almas, v. 12, n. 2, p.27-31, 1990.

CONDIT, I. J. Figs Varieties: A monograph. Hilgardia: University of California, v.23, n.11, 1955. p. 323-538.

CORRÊA, L. S.; BOLIANI, A. C. (Ed.) Cultura da Figueira do Plantio a Comercialização. São Paulo: FUNEP, 1999. p.25-35

Cultura Agronômica, Ilha Solteira, v.24, n.2, p.225-233, 2015 
EMPRESA BRASILEIRA DE PESQUISA AGROPECUÁRIA - EMBRAPA. Sistema brasileiro de classificação de solos. 2.ed. Rio de Janeiro: Centro Nacional de Pesquisa de Solos, 2006. 306 p.

GONÇALVES, C. A. A.; LIMA, L. C. D. O.; LOPES, P. S. N.; SOUZA, M. T. D. Poda e sistemas de condução na produção de figos verdes. Pesquisa Agropecuária Brasileira, Brasília, v. 41, n. 6, p.955-961, 2006.

IEA - Instituto De ECONOMiA AGRÍCOLA. A Cultura do figo em São Paulo. Disponível em:< http://www.iea.sp.gov.br/>. Acesso em: abr 2008.

MAIORANO, J. A.; ANTUNES, L. E. C.; REGINA, M. D. A.; ABRAHÃO, E.; PEREIRA, A. F. Botânica e caracterização de cultivares de figueira. Informe Agropecuário, Belo Horizonte, v.18, n.188, p.22-24, 1997.

PEREIRA, F. M. Cultura da figueira. Piracicaba: Livroceres, 1981. 73 p.

SANTOS, S. C. Efeitos da época de poda e do número de ramos sobre o desenvolvimento, produção e rentabilidade da figueira (Ficus carica L.), cultivada em Selvíria-MS. 1997. 67 f. Dissertação (Mestrado em Agronomia - Produção Vegetal) Faculdade de Engenharia de Ilha Solteira, Universidade Estadual Paulista "Julio Mesquita Filho", Ilha Solteira, 1997.

SIMÃO, S. Tratado de fruticultura. Piracicaba: FEALQ, 1998. 760 p.

SOUZA, C. S. S. Estudo de ambientes de enraizamento, tempo de imersão em AIB, estratificação a frio e enxertia de mesa na figueira. 2008. 104 f. Tese (Doutorado em Agronomia) - Faculdade de Engenharia, Universidade Estadual Paulista "Júlio de Mesquita Filho", Ilha Solteira, 2008.

VIEIRA, A.; CELESTINO, R. C. A.; IDE, C. D. Efeito de diferentes épocas de poda na produção de figo verde, na região das baixadas litorâneas do estado do Rio de Janeiro. In: CONGRESSO BRASILEIRO DE FRUTICULTURA, 20., 2008, Vitória. Anais... Vitória: Sociedade Brasileira de Fruticultura, 2008. p. 230-234.

Cultura Agronômica, Ilha Solteira, v.24, n.2, p.225-233, 2015 